\title{
Adsorption of Selected Pharmaceutical Compounds onto Activated Carbon in Dilute Aqueous Solutions Exemplified by Acetaminophen, Diclofenac, and Sulfamethoxazole
}

\author{
E.-E. Chang, ${ }^{1}$ Jan-Chi Wan, ${ }^{2}$ Hyunook Kim, ${ }^{3}$ Chung-Huei Liang, \\ Yung-Dun Dai, ${ }^{2}$ and Pen-Chi Chiang ${ }^{2,4}$ \\ ${ }^{1}$ Department of Biochemistry, Taipei Medical University, Taipei 110, Taiwan \\ ${ }^{2}$ Graduate Institute of Environmental Engineering, National Taiwan University, Taipei 106, Taiwan \\ ${ }^{3}$ Department of Energy and Environmental System Engineering, University of Seoul, Seoul 130-743, Republic of Korea \\ ${ }^{4}$ Carbon Cycle Research Center, National Taiwan University, Taipei 106, Taiwan \\ Correspondence should be addressed to Pen-Chi Chiang; pcchiang@ntu.edu.tw
}

Received 23 January 2015; Accepted 23 March 2015

Academic Editor: Esteban Alonso

Copyright (C) 2015 E.-E. Chang et al. This is an open access article distributed under the Creative Commons Attribution License, which permits unrestricted use, distribution, and reproduction in any medium, provided the original work is properly cited.

\begin{abstract}
The adsorption of three pharmaceuticals, namely, acetaminophen, diclofenac, and sulfamethoxazole onto granular activated carbon (GAC), was investigated. To study competitive adsorption, both dynamic and steady-state adsorption experiments were conducted by careful selection of pharmaceuticals with various affinities and molecular size. The effective diffusion coefficient of the adsorbate was increased with decease in particle size of GAC. The adsorption affinity represented as Langmuir was consistent with the ranking of the octanol-water partition coefficient, $K_{\text {ow }}$. The adsorption behavior in binary or tertiary systems could be described by competition adsorption. In the binary system adsorption replacement occurred, under which the adsorbate with the smaller $K_{\text {ow }}$ was replaced by the one with larger $K_{\mathrm{ow}}$. Results also indicated that portion of the micropores could be occupied only by the small target compound, but not the larger adsorbates. In multiple-component systems the competition adsorption might significantly be affected by the macropores and less by the meso- or micropores.
\end{abstract}

\section{Introduction}

Recently, there are many concerns on the presence of pharmaceuticals and personal care products (PPCPs) in the aquatic environment, for example, rivers, lakes, and wastewater treatment plants. PPCPs are a large group of synthetic chemicals including various therapeutic drugs, nonsteroidal antiinflammatories (NSAIDs), analgesics, antibiotics, antiepileptics, and blood lipid regulators [1-3]. Although PPCPs have been detected only at trace levels in aquatic systems, their potential adverse impact on human and ecological health is high [4]. In this regard, investigation into the fate, transport, and bioaccumulation of PPCPs in the environment is needed. Interaction between PPCPs and aquatic particulates is the first step in the transport of these hazardous chemicals. However, the adsorption behavior of PPCPs onto naturally occurring particulates is difficult to characterize due to the complex nature of the PPCPs compounds, especially in specific functional groups and physicochemical properties, which are further complicated by possible multicomponent and multiphase interactions in the aquatic system.

Activated carbon has been proposed to be an adsorbent for the removal of PPCPs from water due to its unique physical chemical properties such as porosity and large specific surface area in addition to the availability and maturity of adsorption technology [5-8]. Generally, activated carbon is applied at the polishing step for the removal of refractory compounds and precursors of disinfection byproducts in water treatment [9].

Among the wide variety of PPCPs, diclofenac, acetaminophen, and sulfamethoxazole are the most frequently detected. Diclofenac is an analgesic medicine and an NSAID that can 
treat inflammation and pains, with a hydrophobic nature and low water solubility. Acetaminophen is commonly used to treat minor aches and pains and is also a major ingredient of flu-controlling medicine, which is moderately hydrophilic with high water solubility. Sulfamethoxazole is a common antibiotic, that is, bactericide, for the control of infectious diseases and is much more hydrophobic, with water low solubility. Additionally, the molecular size of diclofenac is greater than that of acetaminophen and sulfamethoxazole, which may affect the adsorption behavior toward activated carbon. Much has been reported on the adsorption characteristics of diclofenac [10-15], acetaminophen [13, 16-21], and sulfamethoxazole [14, 22-25] on various adsorbents. Most of these studies were conducted using pure water as matrix with and without natural organic matter being present and were in single-component systems without considering possible competition from other PPCPs.

It should be noted that pharmaceuticals usually occur in multicomponent in the aquatic environment. It is expected that there will be interspecies interactions among these pharmaceuticals, which will affect chemical reactions compared to when only single pharmaceutical is present. However, few studies have considered the effect of competitive adsorption in multicomponent system. The objective of this study, therefore, was to evaluate the competition adsorption among target pharmaceuticals with various molecular sizes and affinities toward activated carbon.

\section{Materials and Methods}

2.1. Adsorbent and Adsorbates. Filtrasorb 400 (F400) made from bituminous coal and manufactured by Calgon Carbon Corporation USA was used in this study. The granular activated carbon (GAC) was washed with deionized water and then desiccated at $178 \mathrm{~K}$ for $24 \mathrm{~h}$. Afterward, the GAC was crushed and sieved into various sizes, that is, 60, 80, 120,230 , and 320 meshes, with average diameter of 0.271 , $0.158,0.073,0.038$, and $0.028 \mathrm{~mm}$, respectively. The following typical physical-chemical properties of GAC were as characterized: specific surface area (BET method) $=1,156 \mathrm{~m}^{2} / \mathrm{g}$; iodine number $=1,077 \mathrm{mg} / \mathrm{g}$; particle density $=0.85 \mathrm{~g} / \mathrm{mL}$; ash content $=5 \%$; macroporous volume $(\psi>50 \mathrm{~nm})=1.5 \mathrm{~cm}^{3} / \mathrm{g}$; micropore volume $(\psi<2 \mathrm{~nm})=0.38 \mathrm{~cm}^{3} / \mathrm{g}$; and isoelectric point $\left(\mathrm{pH}_{\mathrm{pzc}}\right)=8.9$.

Target compounds, that is, diclofenac sodium salt, acetaminophen, and sulfamethoxazole, were purchased from Sigma-Aldrich of high-performance-liquid-chromatograph (HPLC) grade. Table 1 shows the typical physical-chemical properties of the three target compounds studied.

2.2. Batch Adsorption Experiments. The equilibrium and dynamic adsorption for single- and multicomponent systems were conducted in batch experiments at a stirring speed of $140 \mathrm{rpm}$ for $72 \mathrm{~h}$ and $25^{\circ} \mathrm{C}$. When it was to determine the diffusion coefficient, the initial concentration of target compound and GAC dosage were kept constant at 10 and $10 \mathrm{mg} / \mathrm{L}$, respectively, and the particle size of GAC varied from $0.028 \mathrm{~mm}$ (320 meshes) to $0.271-0.758 \mathrm{~mm}(80-60$ meshes). When it was to establish the adsorption isotherms, the initial target compound concentration was varied from 5 to $40 \mathrm{mg} / \mathrm{L}$ while keeping the GAC dosage constant at $10 \mathrm{mg}$ and particle size of $60 \times 80$ mesh for $72 \mathrm{~h}$. The adsorption in binary- and ternary-component systems was conducted following the above procedures except that the initial solute concentration was $10 \mathrm{mg} / \mathrm{L}$ and GAC $(60 \times 80 \mathrm{mesh})$ dosage was $10 \mathrm{mg} / \mathrm{L}$. Supernatants were obtained by filtration using fiberglass membrane (Millex HA $0.45 \mu \mathrm{m}$ filter) and stored at room temperature before analysis for residual concentration of the target pharmaceuticals.

2.3. Analytical Method. The target compounds were analyzed by HPLC/ultraviolet equipped (UV) with a C-18 column (RP Tracer Extrasil ODS2 Micromet, $250 \times 4.6 \mathrm{~mm}, 5 \mu \mathrm{m}$ particle size) at a wavelength of $280 \mathrm{~nm}$. Diclofenac was analyzed using a mobile phase consisting of $50 \%$ ammonium formate $(10 \mathrm{mM})$ and $50 \%$ acetonitrile at a flow rate of $1.25 \mathrm{~mL} / \mathrm{min}$. For acetaminophen and sulfamethoxazole, the mobile phase was 30\% of methanol and 70\% of Milli-Q water and detected at UV wavelengths of 254 and $273 \mathrm{~nm}$, respectively.

\section{Data Analysis}

The adsorption density was determined from the initial and residual concentrations of the adsorbate according to the following expression:

$$
q_{t}=\frac{V}{m}\left(C_{0}-C_{t}\right)
$$

where $q_{t}$ is the adsorption density at time $t(\mathrm{mmol} / \mathrm{g}) ; V$ is the volume of solution (L); $C_{0}$ is the initial solute concentration $(\mathrm{mmol} / \mathrm{L}) ; C_{t}$ is the solute concentration at time $t(\mathrm{mmol} / \mathrm{L})$; and $m$ is the amount of GAC used (g).

3.1. Dynamic Adsorption. In adsorption dynamics, according to the concept of homogeneous particle diffusion, adsorbate diffuses through the liquid film from the solution phase to the particle surface. The effective diffusion coefficient, $D_{e}$ $\left(\mathrm{cm}^{2} / \mathrm{s}\right)$, can be determined by fitting experimental data with the following equation [26]:

$$
-\ln \left(1-x_{(t)}^{2}\right)=2 \frac{\pi^{2} D_{e}}{r^{2}} t,
$$

where $x_{(t)}$ is the fraction of solute adsorbed at time $t(\mathrm{~h})$ and $r$ is the average radius of the particle based on sieve analysis and on the assumption of spherical shape $(\mathrm{cm})$.

The reaction-based adsorption kinetics was described by the Lagergren pseudo-first- and the pseudo-second-order rate equations [18]:

pseudo-first order:

$$
\log \left(q_{e}-q_{t}\right)=\log \left(q_{e}\right)-\frac{k_{1}}{2.303}(t),
$$

pseudo-second order:

$$
\frac{t}{q_{t}}=\frac{1}{k_{2} \times q_{e}^{2}}+\frac{t}{q_{e}},
$$




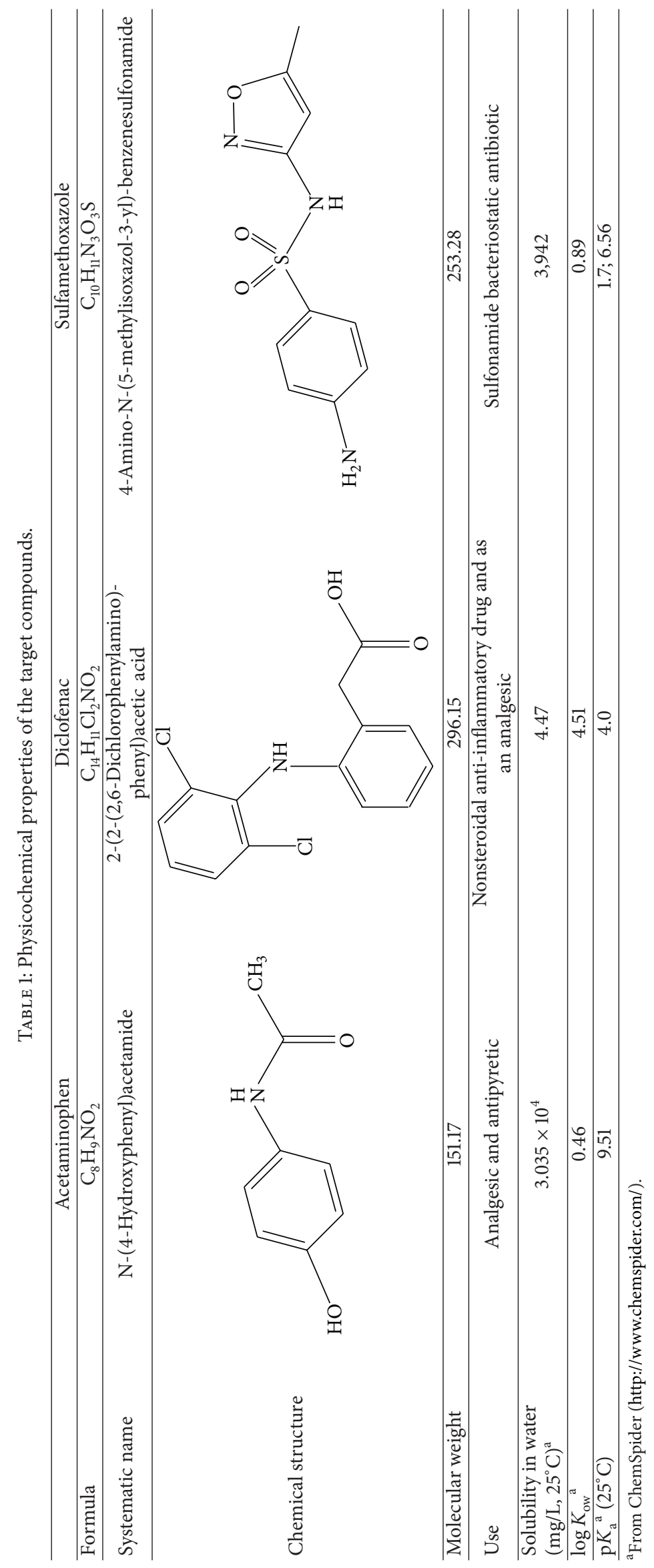


where $q_{e}$ is the equilibrium adsorption density ( $\mathrm{mmol} / \mathrm{g}$ ) and $k_{1}(\mathrm{l} / \mathrm{h})$ and $k_{2}(\mathrm{~g} \mathrm{mmol} / \mathrm{h})$ are the corresponding adsorption rate constants.

3.2. Equilibrium Adsorption. Equilibrium adsorption was analyzed based on the Langmuir isotherm:

$$
\text { Langmuir isotherm: } q_{e}=\frac{q_{\max } b C_{e}}{1+b C_{e}} \text {, }
$$

where $q_{\max }(\mathrm{mmol} / \mathrm{g})$ and $b(\mathrm{~L} / \mathrm{mmol})$ are the maximum (or monolayer coverage density) and Langmuir constants, respectively; $C_{e}$ is the equilibrium solute concentration $(\mathrm{mmol} / \mathrm{L})$.

\subsection{Multicomponent Adsorption}

3.3.1. Noncompetition System. In noncompetition binary adsorption system, it is assumed that adsorption sites are mutually or partly independent and that there is no adsorption interference by the solutes [19]. The adsorption isotherm was written as follows:

$$
\begin{aligned}
& q_{e, A}=\frac{q_{\max , A} b_{A} C_{e, A}}{1+b_{A} C_{e, A}}+\frac{q_{\max , B} b_{B} C_{e, A}}{1+b_{B} C_{e, A}}, \\
& q_{e, B}=\frac{q_{\max , B} b_{B} C_{e, B}}{1+b_{B} C_{e, B}}+\frac{q_{\max , A} b_{A} C_{e, B}}{1+b_{A} C_{e, B}},
\end{aligned}
$$

where $q_{e, A}$ and $q_{e, B}(\mathrm{mmol} / \mathrm{g})$ are the equilibrium adsorption density of the multicomponent adsorption of compounds $A$ and $B$, respectively; $q_{\max , A}(\mathrm{mmol} / \mathrm{g})$ and $q_{\max , B}(\mathrm{mmol} / \mathrm{g})$ are the maximum adsorption density of $A$ and $B$ in singlecomponent system, respectively (from (5)); $b_{A}(\mathrm{~L} / \mathrm{mmol})$ and $b_{B}(\mathrm{~L} / \mathrm{mmol})$ are the Langmuir constants for $A$ and $B$ in the single-component solution, respectively (from (5)); $C_{e, A}$ $(\mathrm{mmol} / \mathrm{L})$ and $C_{e, B}(\mathrm{mmol} / \mathrm{L})$ are the equilibrium concentrations of the multicomponent adsorption for $A$ and $B$, respectively.

3.3.2. Competition System. In a binary system, when adsorption sites are mutually or partially dependent and there is adsorption interference by the solute, competition adsorption occurs [19]. The following modified Langmuir adsorption isotherm can be used to describe the competition adsorption density at equilibrium [22]:

$$
q_{e, i}=\frac{q_{\max , i} b_{i} C_{e, i}}{1+\sum_{j=1}^{N} b_{j} C_{e, j}}
$$

where $q_{e, i}$ is the equilibrium adsorption density of the multicomponent adsorption of the $i$ th compound ( $\mathrm{mmol} / \mathrm{g}$ ); $q_{\max , i}$ and $b_{i}(\mathrm{~L} / \mathrm{mmol})$ are Langmuir parameters obtained in the single-component solution for the $i$ th adsorbate; and $C_{e, i}$ $(\mathrm{mmol} / \mathrm{L})$ is the equilibrium concentration of the multicomponent adsorption of the $i$ th compound.
At sufficiently high concentration of the adsorbates, $1<$ $b_{A} C_{e, A}$ and $1<b_{B} C_{e, A}$. Equations (6) can be simplified to the following:

$$
\begin{aligned}
& \frac{C_{e, A}}{C_{e, B} q_{e, A}}=\frac{b_{B}}{q_{\max , A} B_{A}}+\frac{C_{e, A}}{q_{\max , A} b_{A}}, \quad \text { with respect to } A, \\
& \frac{C_{e, B}}{C_{e, A} q_{e, B}}=\frac{b_{A}}{q_{\max , B} B_{B}}+\frac{C_{e, B}}{q_{\max , B} b_{B}}, \quad \text { with respect to } B .
\end{aligned}
$$

The average relative error (ARE) [22] was used to evaluate the precision of fitting between the experimental and calculated data in the binary system and is expressed as

$$
\mathrm{ARE}=\sqrt{\sum_{i=1}^{N}\left(1-\frac{q_{e, \mathrm{cal}, i}}{q_{e, \exp , i}}\right)^{2}} \times \frac{100}{N}
$$

where $q_{e, \mathrm{cal}, i}$ and $q_{e, \exp , i}$ are the predicted and experimental equilibrium adsorption capacities of the $i$ th component ( $\mathrm{mmol} / \mathrm{g}$ ) and $N$ is the number of experimental data.

\section{Results and Discussion}

\subsection{Simple Component System}

4.1.1. Determination of $D_{e}$. Figure 1 displays the dynamic adsorption of diclofenac, acetaminophen, and sulfamethoxazole onto GAC at various particle sizes. Results revealed that the adsorption density was influenced by the particle size of GAC; that is, finer particles exhibited higher adsorption density than coarser ones. The effect of particle size on adsorption density could be attributed partially to the increase in specific surface area and monolayer adsorption on the exterior surfaces of the carbon [23].

The $D_{e}$ was obtained from the slope of the plot of adsorption density versus time in the range of 0 to $0.5 \mathrm{~h}$ according to (2) and shown in Table 2. For a single compound, the $D_{e}$ decreased as the particle size of GAC decreased, but the trend for diclofenac was less obvious than that for the other two compounds. Equation (2) also shows that the effective diffusion coefficient is in inverse proportion to the square of particle radius under a certain condition. In general, the relative standard deviations of $D_{e}$ for the three compounds ranged from 0.20 to $0.28 \times 10^{-9} \mathrm{~cm}^{2} / \mathrm{s}$, which shows the $D_{e}$ only varied in a very limited extent with the particle size of the GAC. If liquid film diffusion control was assumed as the main resistance of the overall adsorption process, smaller particles could provide less resistance and hence increase the effective diffusion coefficient. However, in this study the $D_{e}$ and the GAC particle size exhibited an inverse relationship which implies that the liquid film diffusion might not be the main control resistance.

It was noted that the $D_{e}$ of the selected compounds have the same order; that is, the average $D_{e}$ of acetaminophen, diclofenac, and sulfamethoxazole were $5.73 \times 10^{-9}, 3.32 \times$ $10^{-9}$, and $6.89 \times 10^{-9} \mathrm{~cm}^{2} / \mathrm{s}$, respectively, without any explicit relationship with the target compound properties, for example, molecular weight. 


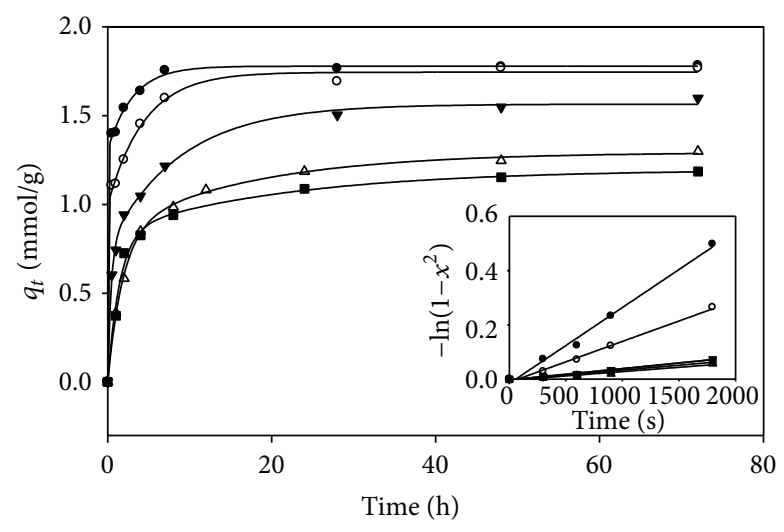

- Smaller than 320 meshes

- 230-320 meshes

v 120-230 meshes $\triangle 80-120$ meshe

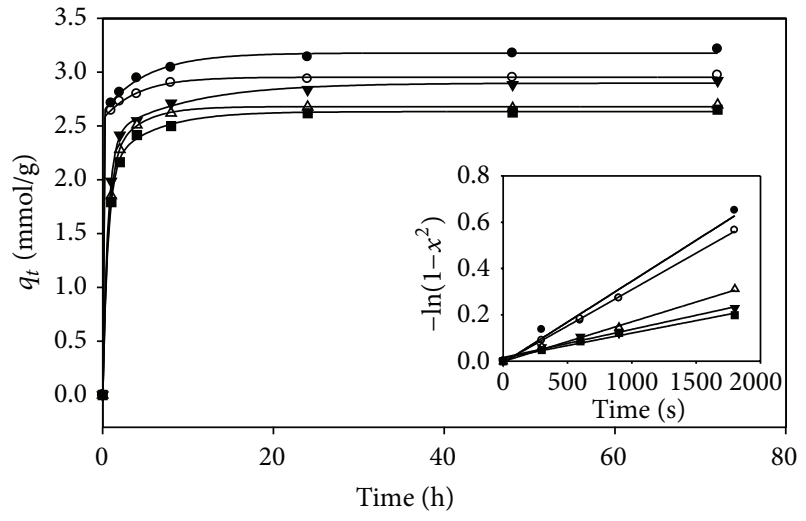

- Smaller than 320 meshes

- 230-320 meshes

$\triangle 80-120$ meshes

v 120-230 meshes

(b)

(a)

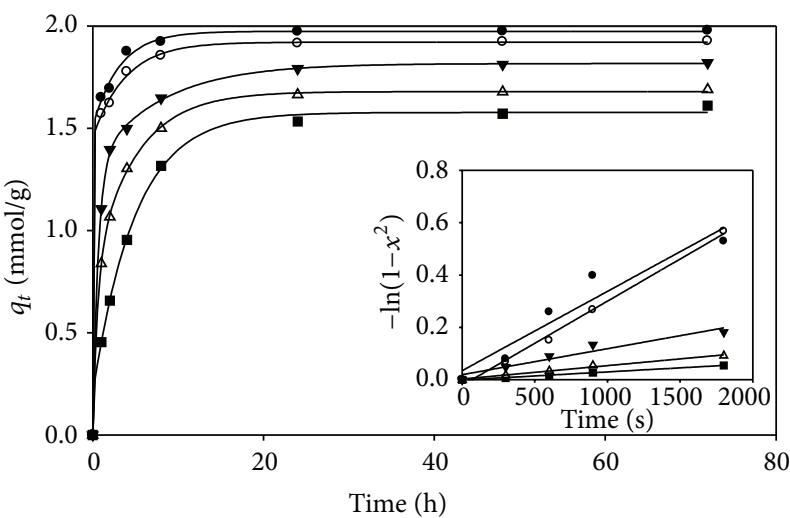

- Smaller than 320 meshes

- 230-320 meshes

v 120-230 meshes $\triangle 80-120$ meshes

- 60-80 meshes

(c)

Figure 1: Effect of particle size on adsorption capacity of (a) diclofenac, (b) acetaminophen, and (c) sulfamethoxazole (stirring speed of $140 \mathrm{rpm}$ for $72 \mathrm{~h}$ and $25^{\circ} \mathrm{C}$. The initial concentration of each target compound was $10 \mathrm{mg} / \mathrm{L}$ ).

TABLE 2: Effective diffusion coefficient of acetaminophen, diclofenac, and sulfamethoxazole onto GAC.

\begin{tabular}{lccc}
\hline Particle size (mesh) & & Effective diffusion coefficient $\left(10^{-9} \mathrm{~cm}^{2} / \mathrm{s}\right)$ & Sulfamethoxazole \\
\hline $60 \times 80$ & Acetaminophen & 4.75 & 9.33 \\
$80 \times 120$ & 7.47 & 3.82 & 8.65 \\
$120 \times 230$ & 6.43 & 2.73 & 7.46 \\
$230 \times 320$ & 6.11 & 2.63 & 5.74 \\
$<320$ & 5.20 & 2.65 & 3.29 \\
\hline Average \pm standard deviation & 3.44 & $3.32 \pm 0.78$ & $6.89 \pm 1.90$ \\
\hline Relative standard deviation & $5.73 \pm 1.13$ & 0.23 & 0.28 \\
\hline
\end{tabular}

4.1.2. Adsorption Kinetics. A kinetic study was conducted to obtain empirical or semiempirical equations for the further design and operation of the adsorption process. The rate constants were calculated according to the Lagergren pseudo-first-order (3) and the pseudo-second-order kinetic equations (4). The regression coefficient by the pseudo-firstorder equation (0.96-0.98) was slightly smaller than that by the pseudo-second-order equation $(>0.99)$, which indicated that the adsorption could follow both kinetic patterns but preferred the pseudo-second-order reaction. Figure 2 shows 


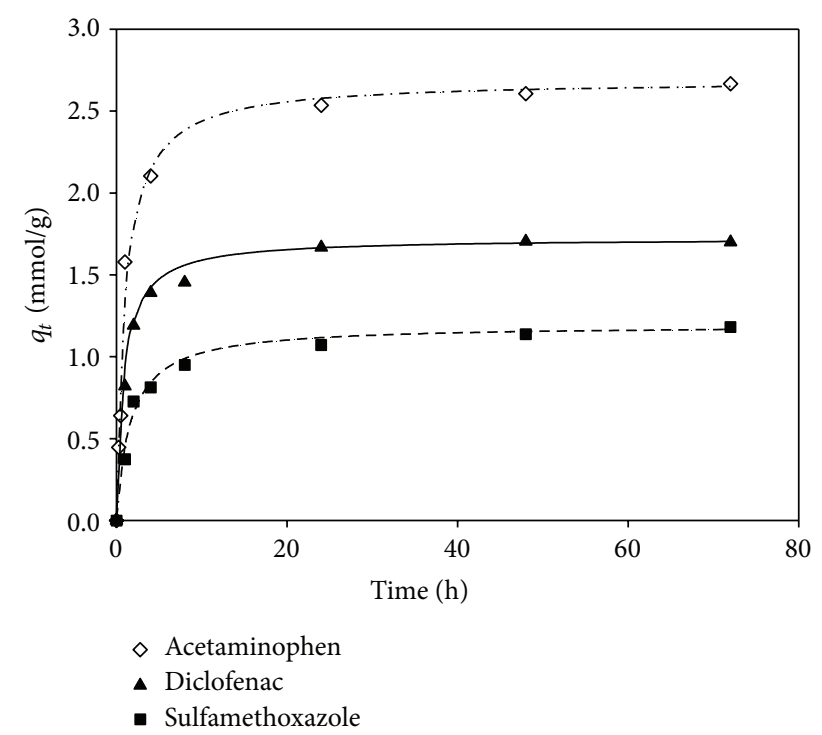

FIGURE 2: Determination of the pseudo-second-order kinetic model onto GAC; pseudo-second-order kinetic model: diclofenac, acetaminophen, and sulfamethoxazole (stirring speed of $140 \mathrm{rpm}$ in $25^{\circ} \mathrm{C}$ with particle size of $60 \times 80$ mesh. The initial concentration of each target compound was $10 \mathrm{mg} / \mathrm{L}$ ).

the results of the experimental data and the calculated data by the pseudo-second-order kinetic equation with the rate constants of $1.59 \times 10^{-5}, 5.74 \times 10^{-6}$, and $1.07 \times 10^{-5}(\mathrm{~g}$ $\mathrm{mmol} / \mathrm{h}$ ) for acetaminophen, diclofenac, and sulfamethoxazole, respectively, which were in inverse proportion to the molecular size. In general, the adsorption of organic micropollutants onto GAC could be described in a number of heterogeneous steps between solids and fluids, including (1) mass transport processes, for example, solute diffusion through the liquid film surrounding the particle (surface diffusion) and solute diffusion through the sorbent matrix of the GAC (intraparticle diffusion), and (2) chemical reaction by which the adsorbates form chemical bonding with the functional groups on the matrix surface.

4.1.3. Adsorption Isotherm. Table 3 presents the equilibrium adsorption coefficients determined from the Langmuir isotherm. For the Langmuir isotherm, the maximum equilibrium adsorption densities $\left(q_{\max }\right)$ of acetaminophen, diclofenac, and sulfamethoxazole were $3.82,1.30$, and $1.80(\mathrm{mmol} / \mathrm{g})$, respectively, which decrease with the molecular weight of adsorbate; that is, the smallest compound, acetaminophen, exhibited the highest adsorption density whereas diclofenac had the lowest adsorption density.

The Langmuir adsorption constant, $b$, could be used as an indicator of the extent of affinity between the adsorbate and the adsorbent; that is, the higher $b$ value represents greater affinity of the adsorbent [24, 25]. From Table 3, it is clear that the $b$ values are consistent with the ranking of the octanol-water partition coefficient $\left(\log K_{\mathrm{ow}}\right.$, shown in Table 1) of the solute. From the result it was observed that, for larger adsorbates such as diclofenac, the limiting factor for
TABLE 3: Parameters of Langmuir and Freundlich isotherms in single-component system onto GAC.

(a)

\begin{tabular}{lccc}
\hline & \multicolumn{3}{c}{ Langmuir isotherm } \\
& $q_{e}(\mathrm{mmol} / \mathrm{g})$ & $q_{\max }(\mathrm{mmol} / \mathrm{g})$ & $b(\mathrm{~L} / \mathrm{mmol})$ \\
\hline Acetaminophen & 2.99 & 3.82 & 26.28 \\
Diclofenac & 1.28 & 1.30 & 794.85 \\
Sulfamethoxazole & 1.76 & 1.80 & 167.17 \\
\hline
\end{tabular}

(b)

\begin{tabular}{lcc}
\hline & \multicolumn{2}{c}{ Freundlich isotherm } \\
& $n$ & $K\left(\mathrm{mmol}^{1-1 / n} \mathrm{~L}^{1 / n} / \mathrm{g}\right)$ \\
\hline Acetaminophen & 2.87 & 5.81 \\
Diclofenac & 13.00 & 1.59 \\
Sulfamethoxazole & 4.62 & 2.97 \\
\hline
\end{tabular}

adsorption was not the mass transfer rate but the access to the micropores.

Table 4 shows the adsorption behavior, represented in the maximum adsorptive density $\left(q_{\max }\right)$ and the Langmuir constant $(b)$, of various adsorbents. For acetaminophen, the results were in agreement with those reported by others $[27,28]$. For diclofenac, GAC exhibited favorable adsorption characteristics in both affinity and capacity compared to chitosan or organo-zeolites [29-31]. In contrast, the adsorption capacity of GAC toward sulfamethoxazole was nearly identical to that of mineral-zeolite [32]. Mineral-zeolites had a porous structure that could accommodate a wide variety of cations, such as $\mathrm{Na}^{+}, \mathrm{K}^{+}, \mathrm{Ca}^{2+}$, and $\mathrm{Mg}^{2+}$, which could provide extra adsorption via formation of specific chemical bonding and resulted in higher adsorption capacity. In general, activated carbon, either powder or granular, was able to provide sufficient adsorption capacity toward the target compounds studied.

\subsection{Binary System}

4.2.1. Adsorption Kinetics. Figure 3 shows the kinetic adsorption in binary systems. The adsorption density of acetaminophen (Figure 3(a) for diclofenac; Figure 3(c) for sulfamethoxazole) increased rapidly at the onset of the adsorption experiment due to its relatively high diffusivity and then decreased slightly to reach a constant value at steady-state. Results showed that acetaminophen exhibited less affinity than diclofenac or sulfamethoxazole. It is likely that the adsorbed acetaminophen could be replaced by diclofenac or sulfamethoxazole indicated in the decrease in adsorption after it reached a plateau when the reaction increased (Figures 3(a) and 3(c)).

Furthermore, the adsorption density of acetaminophen in the presence of diclofenac (Figure 3(a)) was nearly identical to that in the presence of sulfamethoxazole (Figure 3(c)), that is, $0.6 \mathrm{mmol} / \mathrm{g}$, which indicated that portion of the micropores could be occupied only by the smallest target compound (acetaminophen), but not by sulfamethoxazole or diclofenac. Consequently, the steady-state adsorption density 
TABLE 4: Comparison of Langmuir isotherm of acetaminophen, diclofenac, and sulfamethoxazole onto various adsorbents.

\begin{tabular}{|c|c|c|c|c|c|c|}
\hline \multirow{2}{*}{ Adsorbent } & \multicolumn{2}{|c|}{ Acetaminophen } & \multicolumn{2}{|c|}{ Diclofenac } & \multicolumn{2}{|c|}{ Sulfamethoxazole } \\
\hline & $q_{\max }(\mathrm{mmol} / \mathrm{g})$ & $b(\mathrm{~L} / \mathrm{mmol})$ & $q_{\max }(\mathrm{mmol} / \mathrm{g})$ & $b(\mathrm{~L} / \mathrm{mmol})$ & $q_{\max }(\mathrm{mmol} / \mathrm{g})$ & $b(\mathrm{~L} / \mathrm{mmol})$ \\
\hline $\begin{array}{l}\text { Granular activated } \\
\text { carbon }\end{array}$ & $\begin{array}{l}3.82 \text { (this study); } \\
1.10 \text { to } 1.58[33] \\
1.32 \text { to } 1.77[17]\end{array}$ & $\begin{array}{c}26.28 \text { (this study); } \\
63.3 \text { to } 97.8 \text { [33]; } \\
16.3 \text { to } 54.4[17]\end{array}$ & 1.30 (this study) & 794.85 (this study) & 1.80 (this study) & $\begin{array}{l}167.17 \text { (this } \\
\text { study) }\end{array}$ \\
\hline $\begin{array}{l}\text { Powdered activated } \\
\text { carbon }\end{array}$ & n.a. & n.a. & n.a. & n.a. & $\begin{array}{c}0.73[23] ; \\
0.26 \text { to } 0.43[24]\end{array}$ & $\begin{array}{c}185[23] ; \\
0.65 \text { to } 1.56[24]\end{array}$ \\
\hline Chitosan & n.a. & n.a. & $0.53[34]$ & $25.7[34]$ & n.a. & n.a. \\
\hline $\begin{array}{l}\text { Aptamer-based } \\
\text { column }\end{array}$ & n.a. & n.a. & $0.09[26]$ & 0.0001 to 0.0002 [26] & n.a. & n.a. \\
\hline Organo-zeolite & n.a. & n.a. & $0.13[20]$ & $42.7[20]$ & 0.71 to $1.90[25]$ & 35 to $286[25]$ \\
\hline
\end{tabular}

n.a.: not available.

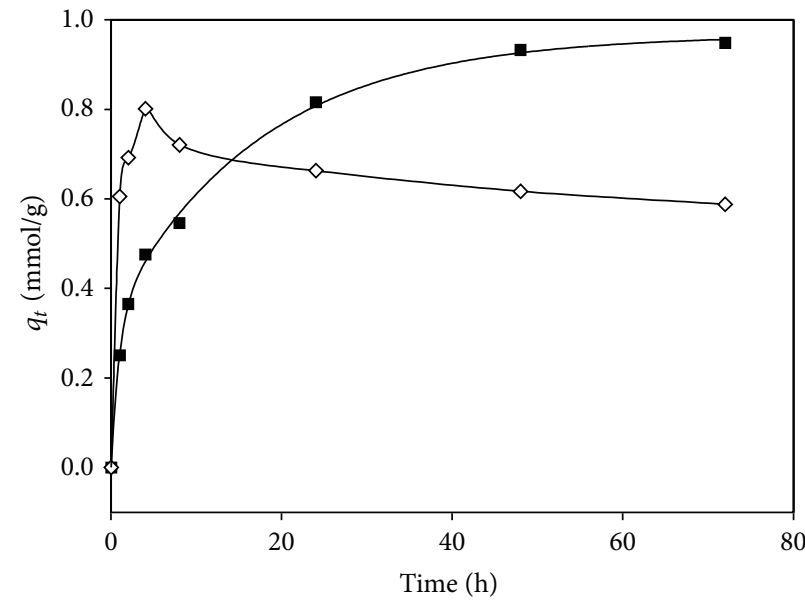

$\diamond$ Acetaminophen

- Diclofenac

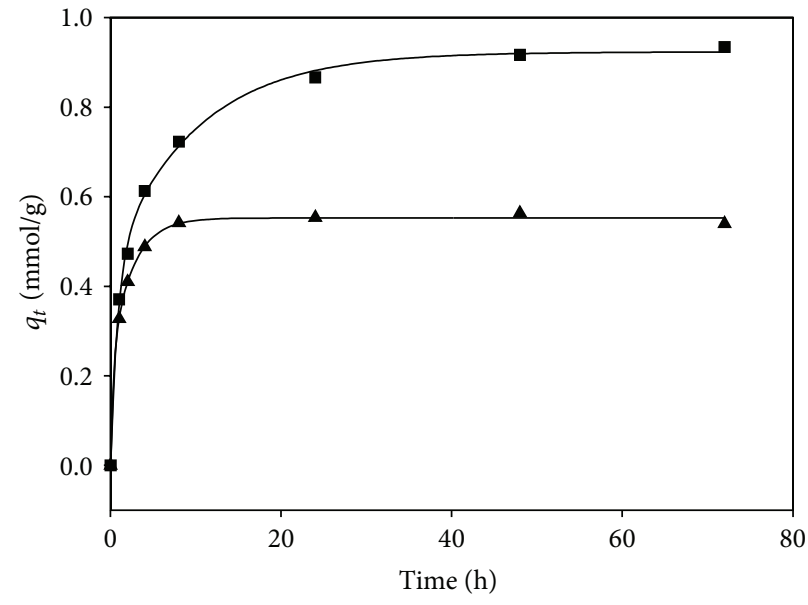

Diclofenac

- Sulfamethoxazole

(a)

(b)

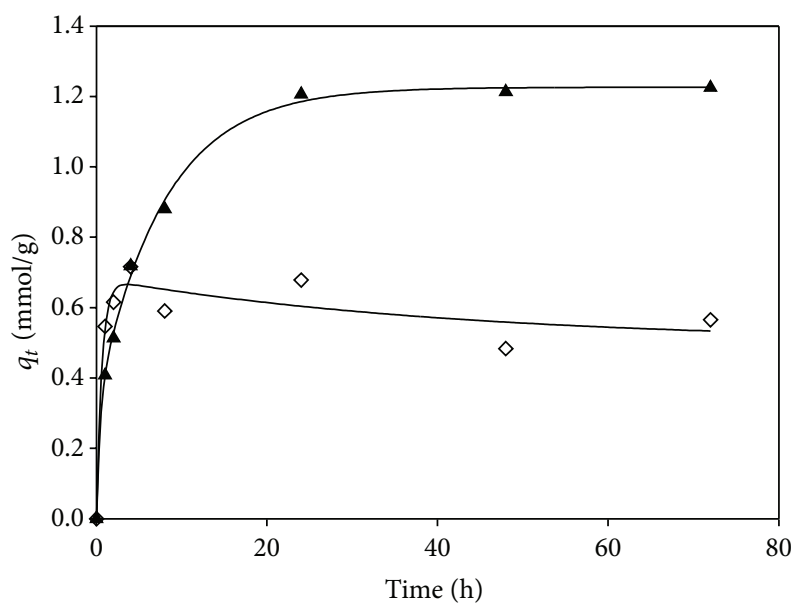

- Sulfamethoxazole

$\diamond$ Acetaminophen

(c)

Figure 3: The adsorption capacity of (a) diclofenac and acetaminophen, (b) diclofenac and sulfamethoxazole, and (c) acetaminophen and sulfamethoxazole onto GAC in binary mixture (stirring speed of $140 \mathrm{rpm}$ for $72 \mathrm{~h}$ and $25^{\circ} \mathrm{C}$. The initial concentration of each target compound was $10 \mathrm{mg} / \mathrm{L}$ ). 


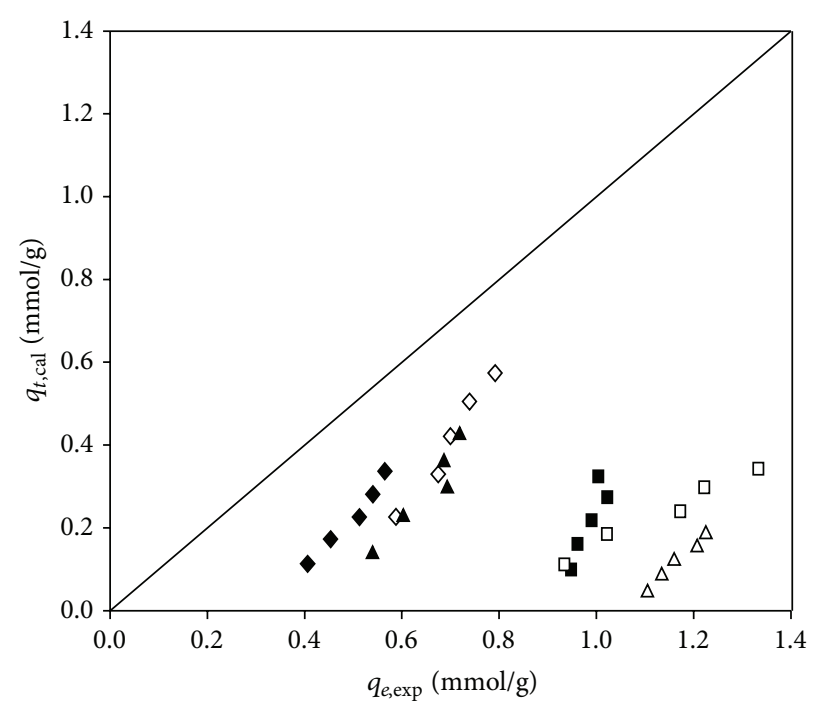

$\diamond$ Acetaminophen in diclofenac

$\checkmark$ Diclofenac in sulfamethoxazole

$\triangle$ Sulfamethoxazole in acetaminophen

- Acetaminophen in sulfamethoxazole

- Diclofenac in acetaminophen

- Sulfamethoxazole in diclofenac

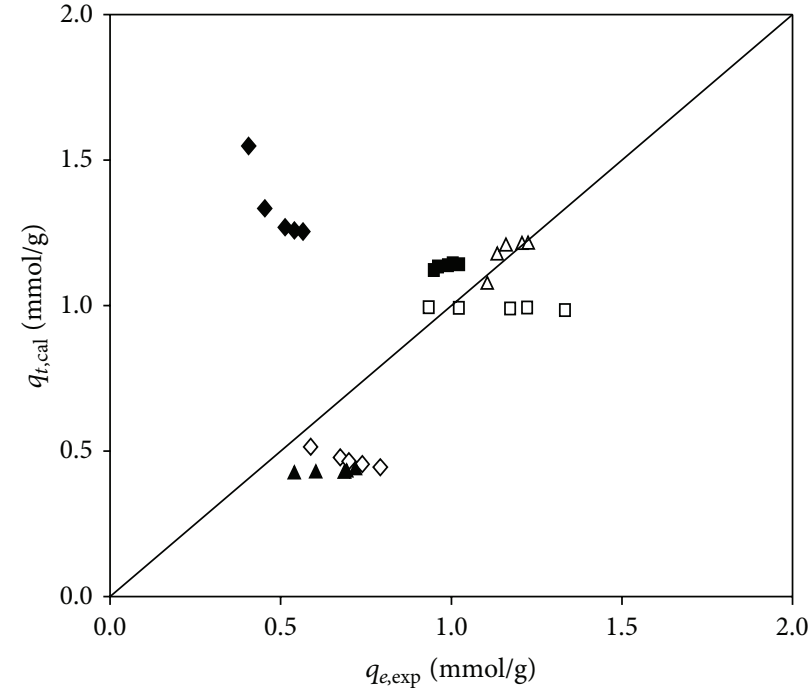

$\diamond$ Acetaminophen in diclofenac

$\square$ Diclofenac in sulfamethoxazole

$\triangle$ Sulfamethoxazole in acetaminophen

- Acetaminophen in sulfamethoxazole

- Diclofenac in acetaminophen

A Sulfamethoxazole in diclofenac

(a)

(b)

FIGURE 4: Comparison of the experimental and calculated data according to (a) noncompetitive adsorption and (b) competitive adsorption in binary components.

of acetaminophen in the highly competitive system (i.e., in the presence of diclofenac) could be estimated based on the micropores whereas its adsorption density in the lowcompetitive system (i.e., in the presence of sulfamethoxazole) was not correlated with the pore size. On the other hand, the differences of the steady-state adsorption density between the diclofenac-acetaminophen (Figure 3(a)) and diclofenacsulfamethoxazole (Figure 3(b)) systems were close, which were correspondent to the difference between their affinities. It was thus concluded that before steady-state adsorption, the competition and thus replacement might occur in the system in which the difference in adsorption density between the two adsorbates was significant. After steady-state, the adsorption density was primarily determined by the affinity and the size of the adsorbate.

4.2.2. Competitive or Noncompetitive Adsorption. In a multicomponent system, the adsorption behavior could be classified as noncompetitive or competitive. Noncompetitive adsorption was brought by nonspecific selectivity of the adsorption sites in a multicomponent system. As shown in Figure 4(a), the calculated equilibrium adsorption densities determined by (7) were all underestimated from the experimental data, with ARE over $19 \%$ to $40 \%$, indicating that noncompetitive adsorption failed to describe the adsorption process in the multicomponent system.

On the other hand, the multicomponent nonmodified Langmuir isotherm (6) was able to describe the competitive adsorption behavior (Figure 4(b)). The results of ARE were smaller than $15 \%$, which indicated that competition adsorption was involved in the multicomponent system. However, it should be noted that in the acetaminophen-sulfamethoxazole system, the adsorption density of acetaminophen was underestimated by noncompetition but highly overestimated by competition adsorption. It is noted that the difference of the $\log K_{\text {ow }}$ values of these two compounds, that is, 0.46 to 0.86 , is much less than that of the acetaminophen-diclofenac and the sulfamethoxazole-diclofenac system. Hence, it could be understood that the acetaminophen-sulfamethoxazole system might be between noncompetition and competition adsorption.

4.3. Multicomponent Systems. The steady-state adsorption densities of the three target compounds in single, binary, and tertiary systems are shown in Table 5. It is obvious that acetaminophen exhibited the greatest loss in adsorption density in multicomponent systems, from single $(2.99 \mathrm{mmol} / \mathrm{g})$ to binary $(0.59 \mathrm{mmol} / \mathrm{g}$ with diclofenac and $0.60 \mathrm{mmol} / \mathrm{g}$ with sulfamethoxazole, resp. $)$ or tertiary $(0.32 \mathrm{mmol} / \mathrm{g})$ systems. As expected, diclofenac exhibited the least decrease in adsorption density from single $(1.28 \mathrm{mmol} / \mathrm{g})$ to binary $(0.96 \mathrm{mmol} / \mathrm{g}$ with acetaminophen and $0.94 \mathrm{mmol} / \mathrm{g}$ with sulfamethoxazole, resp.) or tertiary $(0.83 \mathrm{mmol} / \mathrm{g})$ systems. Consequently, the total adsorption density in the binary system varied in two patterns. The total adsorption density in the binary system would be greater than that in the single diclofenac system. For example, in the diclofenac-sulfamethoxazole system, the total adsorption 
TABLE 5: The adsorption density of each target compound under single, binary, and tertiary systems.

\begin{tabular}{|c|c|c|c|c|c|}
\hline \multirow{2}{*}{ Solute system } & \multirow{2}{*}{ Adsorbate(s) } & \multicolumn{4}{|c|}{ Adsorption density (mmol/L) } \\
\hline & & Acetaminophen & Diclofenac & Sulfamethoxazole & Total \\
\hline \multirow{3}{*}{ Single } & Acetaminophen & 2.99 & - & - & 2.99 \\
\hline & Diclofenac & - & 1.28 & - & 1.28 \\
\hline & Sulfamethoxazole & - & - & 1.76 & 1.76 \\
\hline \multirow{3}{*}{ Binary } & Acetaminophen + diclofenac & 0.59 & 0.96 & - & 1.55 \\
\hline & Diclofenac + sulfamethoxazole & - & 0.94 & 0.52 & 1.46 \\
\hline & Sulfamethoxazole + acetaminophen & 0.60 & - & 1.20 & 1.80 \\
\hline Tertiary & Acetaminophen + diclofenac + sulfamethoxazole & 0.32 & 0.83 & 0.47 & 1.62 \\
\hline
\end{tabular}

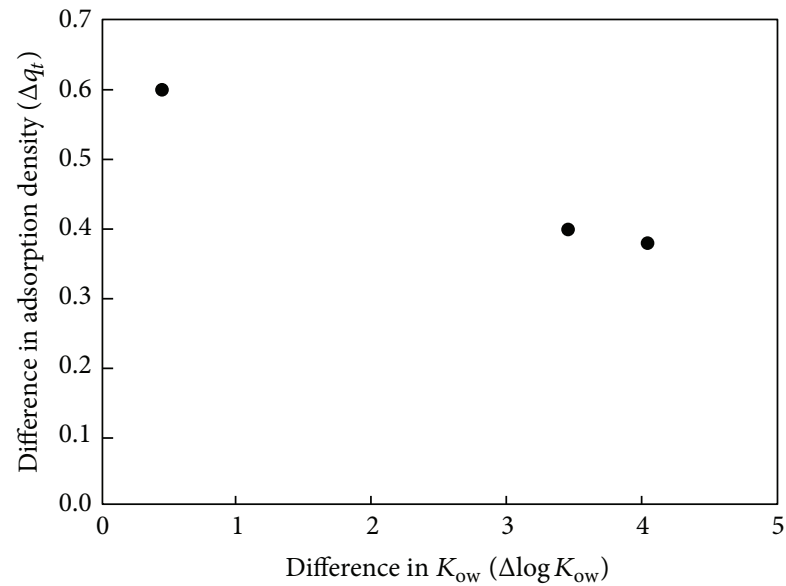

FIGURE 5: The difference in adsorption density and $\log \left(K_{\text {ow }}\right)$ value between two pharmaceuticals.

density increased from 1.28 to $1.46 \mathrm{mmol} / \mathrm{g}$, because of the utilization of the mesopores of the GAC. In contrast, the total adsorption density was decreased from the single acetaminophen $(2.99 \mathrm{mmol} / \mathrm{g})$ system to the acetaminophendiclofenac system $(1.55 \mathrm{mmol} / \mathrm{g})$ and the acetaminophensulfamethoxazole system $(1.80 \mathrm{mmol} / \mathrm{g})$, which indicated that diclofenac or sulfamethoxazole was instrumental in interfering with the adsorption of acetaminophen through competition.

Figure 5 shows the difference in adsorption density and $\log \left(K_{\text {ow }}\right)$ between two pharmaceuticals from Figure 3. It is interesting to note that the decrease in adsorption $\left(\Delta q_{t}\right)$ decreases exponentially with the $\log K_{\mathrm{ow}}$ value $\left(\Delta \log K_{\mathrm{ow}}\right)$. Since the $K_{\text {ow }}$ shows the equilibrium concentration of a compound between octanol and water, in other words, a low $K_{\mathrm{ow}}$ indicating a compound exhibits the hydrophilic and low adsorption affinity. From Figure 5 it is known that as the difference in $\log \left(K_{\text {ow }}\right)$ value increased, the difference in adsorption density would decrease which implied the difference between two adsorption densities would be less significant. In other words, the greater the difference in hydrophobicity, the greater the difference in adsorption density of the target compound with the smaller $K_{\mathrm{ow}}$.

In the tertiary system, the decrease in adsorption density was the highest for acetaminophen, that is, from 2.99 to $0.32 \mathrm{mmol} / \mathrm{g}$ (decrease by approximately $89 \%$ ), and the smallest for diclofenac, that is, from 1.28 to $0.83 \mathrm{mmol} / \mathrm{g}$ (decrease by approximately $35 \%$ ). Results showed that the affinity of the target compounds toward GAC was clearly reflected. On the other hand, even though the adsorption density of each individual pharmaceutical in the mixture was much less than that in the single-solute system, the total adsorption density in the tertiary system was high at $1.62 \mathrm{mmol} / \mathrm{g}$, compared to that of diclofenac only, the diclofenac-acetaminophen, and the diclofenacsulfamethoxazole binary system. The results could be explained by either the restriction of the pore size or succeeding adsorption that formed a multilayer by these pharmaceuticals [23]. It was thus concluded that in the multicomponent systems, which consisted of adsorbates with various affinities and sizes, the competition adsorption might significantly affect the adsorption in the macropores and less with the meso- or micropores.

\section{Conclusions}

The effective diffusion coefficient of the adsorbate in GAC increased as the GAC particles became finer but was not related to the MW. For single-component systems, the kinetics of the adsorption reaction could be described by the pseudo-second-order kinetic expression. Results of the Langmuir adsorption isotherm parameter revealed that $b$ was consistent with the ranking of octanol-water partition coefficient $\left(K_{\mathrm{ow}}\right)$. Compared with other adsorbents such as chitosan or zeolite, activated carbon exhibited the most favorable affinity toward the pharmaceuticals studied.

Based on ARE calculation, the adsorption behavior in binary and tertiary system appeared to be competitive adsorption by nature. In the binary system before steadystate, adsorption replacement occurred when two adsorbates exhibited a significant difference in their affinities, that is, $K_{\text {ow }}$, such as the acetaminophen-diclofenac system. The steady-state adsorption density was primarily determined by the affinity and the size of the adsorbate. The adsorbates with the lowest affinity gave the smallest adsorption density, which indicated that portion of the micropores could be occupied only by the small target compound, but not larger adsorbates. Therefore, in the multicomponent systems when adsorbates with various affinities and sizes were present, competition might significantly affect the adsorption in the macropores and less in the meso- or micropores, which could 
provide a criterion for selecting and optimizing the operating conditions.

\section{Conflict of Interests}

The authors declare that there is no conflict of interests regarding the publication of this paper.

\section{Acknowledgment}

High appreciation goes to Ministry of Science and Technology (MOST) of Taiwan under Grant no. 104-2119-M-002-001 for the financial support.

\section{References}

[1] A. Tauxe-Wuersch, L. F. de Alencastro, D. Grandjean, and J. Tarradellas, "Occurrence of several acidic drugs in sewage treatment plants in Switzerland and risk assessment," Water Research, vol. 39, no. 9, pp. 1761-1772, 2005.

[2] P. H. Roberts and K. V. Thomas, "The occurrence of selected pharmaceuticals in wastewater effluent and surface waters of the lower Tyne catchment," Science of the Total Environment, vol. 356, no. 1-3, pp. 143-153, 2006.

[3] O. A. H. Jones, N. Voulvoulis, and J. N. Lester, "The occurrence and removal of selected pharmaceutical compounds in a sewage treatment works utilising activated sludge treatment," Environmental Pollution, vol. 145, no. 3, pp. 738-744, 2007.

[4] Y. Kim, K. Choi, J. Jung, S. Park, P.-G. Kim, and J. Park, "Aquatic toxicity of acetaminophen, carbamazepine, cimetidine, diltiazem and six major sulfonamides, and their potential ecological risks in Korea," Environment International, vol. 33, no. 3, pp. 370-375, 2007.

[5] Y. Yoon, P. Westerhoff, S. A. Snyder, and M. Esparza, "HPLCfluorescence detection and adsorption of bisphenol $\mathrm{A}, 17 \beta$ estradiol, and $17 \alpha$-ethynyl estradiol on powdered activated carbon," Water Research, vol. 37, no. 14, pp. 3530-3537, 2003.

[6] K. J. Choi, S. G. Kim, C. W. Kim, and S. H. Kim, "Effects of activated carbon types and service life on removal of endocrine disrupting chemicals: amitrol, nonylphenol, and bisphenol-A," Chemosphere, vol. 58, no. 11, pp. 1535-1545, 2005.

[7] A. M. Redding, F. S. Cannon, S. A. Snyder, and B. J. Vanderford, "A QSAR-like analysis of the adsorption of endocrine disrupting compounds, pharmaceuticals, and personal care products on modified activated carbons," Water Research, vol. 43, no. 15, pp. 3849-3861, 2009.

[8] G. Liu, J. Ma, X. Li, and Q. Qin, "Adsorption of bisphenol A from aqueous solution onto activated carbons with different modification treatments," Journal of Hazardous Materials, vol. 164, no. 2-3, pp. 1275-1280, 2009.

[9] P. Kulkarni and S. Chellam, "Disinfection by-product formation following chlorination of drinking water: artificial neural network models and changes in speciation with treatment," Science of the Total Environment, vol. 408, no. 19, pp. 4202-4210, 2010.

[10] Z.-H. Xiong, L. Wang, J.-G. Zhou, and J.-M. Liu, "Thermodynamics and kinetics of adsorption of diclofenac on magnetic multiwalled carbon nanotubes in an aqueous solution," Acta Physico-Chimica Sinica, vol. 26, no. 11, pp. 2890-2898, 2010.

[11] I. Cabrita, B. Ruiz, A. S. Mestre, I. M. Fonseca, A. P. Carvalho, and C. O. Ania, "Removal of an analgesic using activated carbons prepared from urban and industrial residues," Chemical Engineering Journal, vol. 163, no. 3, pp. 249-255, 2010.

[12] P. Xiao, Y. Dudal, P. F.-X. Corvini, and P. Shahgaldian, "Polymeric cyclodextrin-based nanoparticles: synthesis, characterization and sorption properties of three selected pharmaceutically active ingredients," Polymer Chemistry, vol. 2, no. 1, pp. 120-125, 2011.

[13] I. Vergili and H. Barlas, "Removal of selected pharmaceutical compounds from water by an organic polymer resin," Journal of Scientific and Industrial Research, vol. 68, no. 5, pp. 417-425, 2009.

[14] S. W. Nam, D. J. Choi, S. K. Kim, N. Her, and K. D. Zoh, "Adsorption characteristics of selected hydrophilic and hydrophobic micropollutants in water using activated carbon," Journal of Hazardous Materials, vol. 270, pp. 144-152, 2014.

[15] V. Rakić, V. Rac, M. Krmar, O. Otman, and A. Auroux, "The adsorption of pharmaceutically active compounds from aqueous solutions onto activated carbons," Journal of Hazardous Materials, vol. 282, pp. 141-149, 2015.

[16] E. Çahşkan and S. Göktürka, "Adsorption characteristics of sulfamethoxazole and metronidazole on activated carbon," Separation Science and Technology, vol. 45, pp. 244-255, 2010.

[17] J. Akhtar, N. S. Amin, and A. Aris, "Combined adsorption and catalytic ozonation for removal of sulfamethoxazole using $\mathrm{Fe}_{2} \mathrm{O}_{3} / \mathrm{CeO}_{2}$ loaded activated carbon," Chemical Engineering Journal, vol. 170, no. 1, pp. 136-144, 2011.

[18] D. R. Zuim, D. Carpiné, G. A. R. Distler, A. D. P. Scheer, L. Igarashi-Mafra, and M. R. Mafra, "Adsorption of two coffee aromas from synthetic aqueous solution onto granular activated carbon derived from coconut husks," Journal of Food Engineering, vol. 104, no. 2, pp. 284-292, 2011.

[19] R. C. F. Bonomo and S. H. Saraiva, "Multicomponent adsorption of whey proteins by ion exchanger," Brazilian Journal of Food Technology, vol. 6, pp. 323-326, 2003.

[20] M. Galhetas, A. S. Mestre, M. L. Pinto, I. Gulyurtlu, H. Lopes, and A. Carvalho, "Chars from gasification of coal and pine activated with $\mathrm{K}_{2} \mathrm{CO}_{3}$ : acetaminophen and caffeine adsorption from aqueous solutions," Journal of Colloid and Interface Science, vol. 433, pp. 94-103, 2014.

[21] M. Galhetas, A. S. Mestre, M. L. Pinto, I. Gulyurtlu, H. Lopes, and A. P. Carvalho, "Carbon-based materials prepared from pine gasification residues from acetaminophen adsorption," Chemical Engineering Journal, vol. 240, pp. 344-351, 2014.

[22] S. Kumar, M. Zafar, J. K. Prajapati, S. Kumar, and S. Kannepalli, "Modeling studies on simultaneous adsorption of phenol and resorcinol onto granular activated carbon from simulated aqueous solution," Journal of Hazardous Materials, vol. 185, no. 1, pp. 287-294, 2011.

[23] T. X. Bui and H. Choi, "Adsorptive removal of selected pharmaceuticals by mesoporous silica SBA-15," Journal of Hazardous Materials, vol. 168, no. 2-3, pp. 602-608, 2009.

[24] Y. Bulut and H. Aydin, "A kinetics and thermodynamics study of methylene blue adsorption on wheat shells," Desalination, vol. 194, no. 1-3, pp. 259-267, 2006.

[25] V. C. Srivastava, I. D. Mall, and I. M. Mishra, "Competitive adsorption of cadmium(II) and nickel(II) metal ions from aqueous solution onto rice husk ash," Chemical Engineering and Processing: Process Intensification, vol. 48, no. 1, pp. 370-379, 2009.

[26] C. Valderrama, X. Gamisans, X. de las Heras, A. Farrán, and J. L. Cortina, "Sorption kinetics of polycyclic aromatic hydrocarbons removal using granular activated carbon: intraparticle 
diffusion coefficients," Journal of Hazardous Materials, vol. 157, no. 2-3, pp. 386-396, 2008.

[27] L. C. G. Hoegberg, A.-B. Christophersen, H. R. Christensen, and H. R. Angelo, "Comparison of the adsorption capacities of an activated-charcoal-yogurt mixture versus activatedcharcoal-water slurry in vivo and in vitro," Clinical Toxicology, vol. 43, no. 4, pp. 269-275, 2005.

[28] L. M. Cotoruelo, M. D. Marqués, A. Leiva, J. Rodríguez-Mirasol, and T. Cordero, "Adsorption of oxygen-containing aromatics used in petrochemical, pharmaceutical and food industries by means of lignin based active carbons," Adsorption, vol. 17, no. 3 , pp. 539-550, 2011.

[29] T. O. Carvalho, A. E. B. Matias, L. R. Braga, S. M. Evangelista, and A. G. S. Prado, "Calorimetric studies of removal of nonsteroidal anti-inflammatory drugs diclofenac and dipyrone from water," Journal of Thermal Analysis and Calorimetry, vol. 106, no. 2, pp. 475-481, 2011.

[30] X. Hu, L. Mu, Q. Zhou, J. Wen, and J. Pawliszyn, "ssDNA aptamer-based column for simultaneous removal of nanogram per liter level of illicit and analgesic pharmaceuticals in drinking water," Environmental Science \& Technology, vol. 45, no. 11, pp. 4890-4895, 2011.

[31] D. Krajišnik, A. Daković, M. Milojević et al., "Properties of diclofenac sodium sorption onto natural zeolite modified with cetylpyridinium chloride," Colloids and Surfaces B: Biointerfaces, vol. 83, no. 1, pp. 165-172, 2011.

[32] S. Fukahori, T. Fujiwara, R. Ito, and N. Funamizu, "pHdependent adsorption of sulfa drugs on high silica zeolite: modeling and kinetic study," Desalination, vol. 275, no. 1-3, pp. 237-242, 2011.

[33] T. A. Ternes, M. Meisenheimer, D. McDowell et al., "Removal of pharmaceuticals during drinking water treatment," Environmental Science \& Technology, vol. 36, no. 17, pp. 3855-3863, 2002.

[34] K. Yamamoto, H. Onishi, A. Ito, and Y. Machida, "Medicinal carbon tablets for treatment of acetaminophen intoxication: adsorption characteristics of medicinal carbon powder and its tablets," Chemical and Pharmaceutical Bulletin, vol. 54, no. 3, pp. 359-362, 2006. 

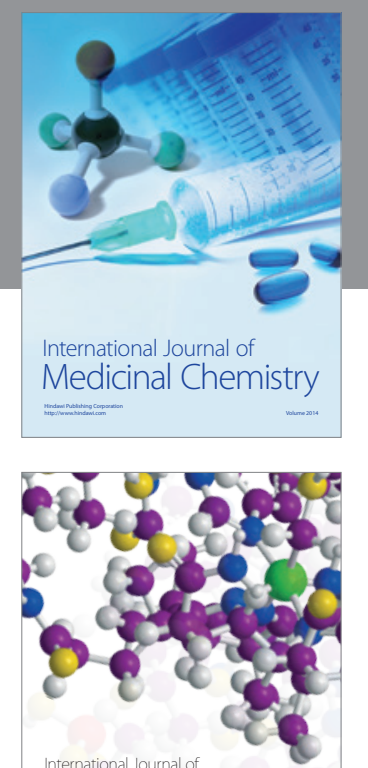

\section{Carbohydrate} Chemistry

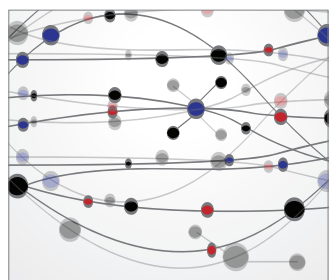

The Scientific World Journal
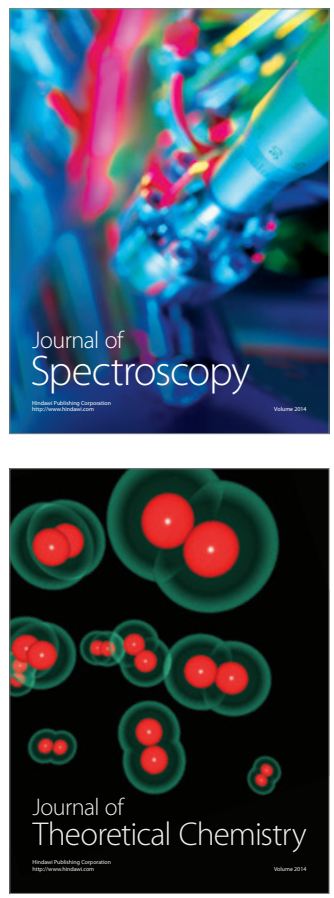
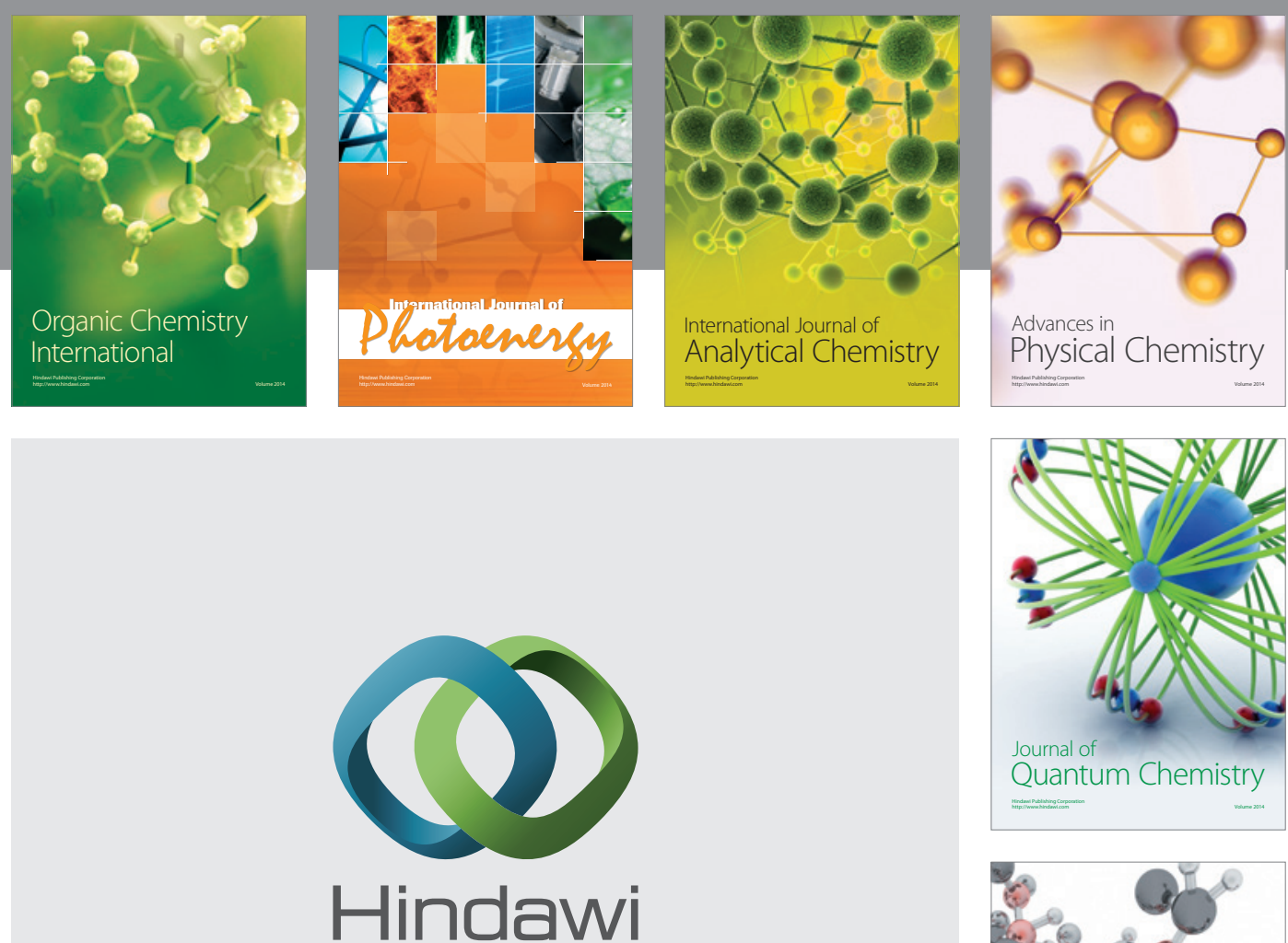

Submit your manuscripts at

http://www.hindawi.com

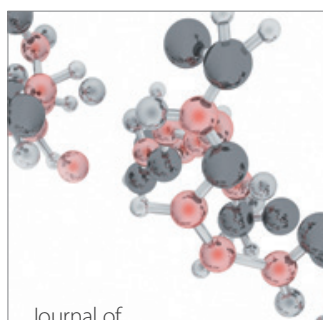

Analytical Methods

in Chemistry

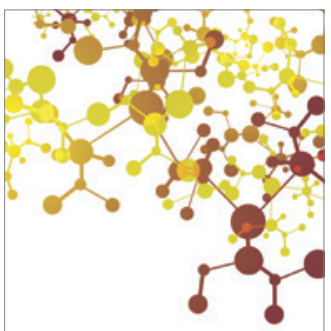

Journal of

Applied Chemistry

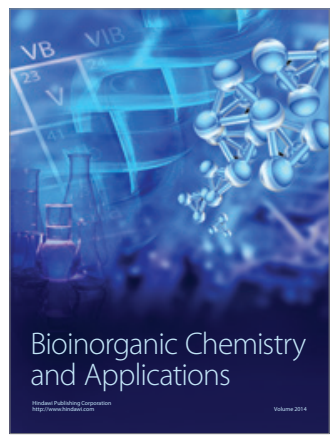

Inorganic Chemistry
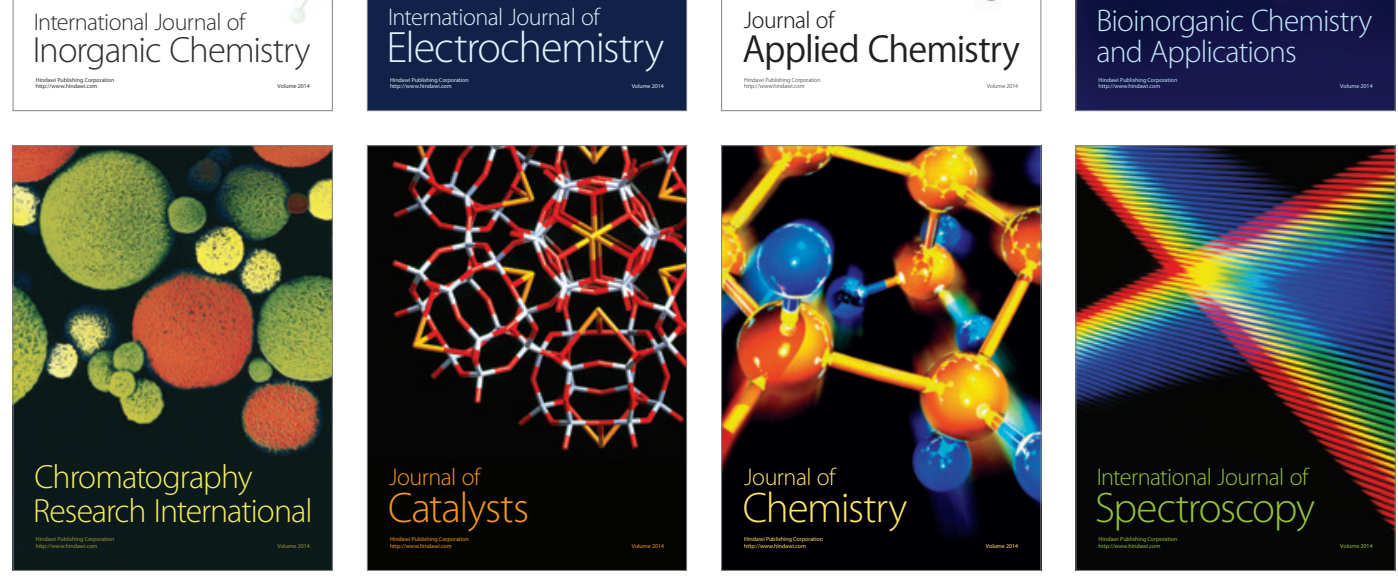